\title{
Impact of Genomics on Chickpea Breeding
}

\author{
Srinivasan Samineni, Mahendar Thudi, Sobhan B. Sajja, \\ Rajeev K. Varshney and Pooran M. Gaur
}

\begin{abstract}
Chickpea is an economical source of vegetable protein for the poor living in the semi-arid regions globally. As a consequence of climate change and increasing climate variability, the incidences of drought and heat stresses and severity of some diseases, such as dry root rot and collar rot, have increased in chickpea crop, resulting in poor and unstable yields. By improoving the efficiency of crop breeding programs, climate resilient varieties with traits desired by the farmers, industries and consumers can be developed more rapidly. Excellent progress has been made in the development of genomic resources for chickpea in the recent past. Several national and international chickpea breeding programs have started utilizing these genomic resources and tools for genetic improvement of complex traits. One of such examples includes the introgression of "QTL-hotspot" containing quantitative trait loci (QTLs) for several drought tolerance-related traits, including root traits, through marker-assisted backcrossing (MABC) for enhancing drought tolerance in popular cultivars. Several drought-tolerant introgression lines with higher yield as compared to the popular cultivars have been identified. Multi-parent advanced generation intercross (MAGIC) populations developed from using 8 parents created large genetic diversity consequently several promising lines. Marker-assisted recurrent selection (MARS) has also been explored for yield improvement in chickpea. Development of diagnostic markers or the identification of candidate genes for several traits is essential for greater use of genomic resources in chickpea improvement.
\end{abstract}

S. Samineni · M. Thudi · S.B. Sajja $\cdot$ R.K. Varshney ·

P.M. Gaur $(\bowtie)$

International Crops Research Institute for the

Semi-Arid Tropics (ICRISAT), Patancheru, India

e-mail: p.gaur@cgiar.org 


\subsection{Introduction}

Chickpea (Cicer arietinum L.) is a cool-season food legume grown mainly in arid and semi-arid regions of the world. Chickpea is cultivated in $13.9 \mathrm{~m}$ ha with a production of $13.6 \mathrm{~m}$ ton during 2014 (FAOSTAT 2016). Its cultivation and consumption are mainly concentrated in South Asia region, where India alone accounts for more than $70 \%$ of global chickpea area and consumption. Due to its cultivation under challenging soil and environmental conditions, the crop is exposed to several biotic and abiotic stresses. As a consequence of climate change, incidence of new races and also new diseases such as dry root rot and collar rot are posing serious threats to chickpea production. Besides classical breeding methods, genomic approaches are particularly useful in handling complex traits, which are usually controlled by several genes and highly influenced by environment. Genomic tools facilitate in the identification of genomic regions/QTLs and favorable alleles of small effects that generally remain unnoticed and are not included in the gene pool used for breeding (Morgante and Salamini 2003; Vaughan et al. 2007).

Most of the qualitative traits are characterized by high heritability and are easy to select for. However, favorable allelic combinations and genetic recombinations for complex traits are difficult to identify through conventional breeding strategies. Advances in genomic technologies enable to capture genome-wide diversity in natural and artificial populations. In recent years, large-scale genomic resources were developed in case of chickpea (Varshney et al. 2010). The draft genome sequence and resequence information of germplasm lines of chickpea (Varshney et al. 2013) including parental lines of several mapping populations (Thudi et al. 2016), varieties (Thudi et al. 2016) provided several thousands of simple sequence repeat (SSR) markers, millions of single nucleotide polymorphism (SNP) and indels for use in genomics-assisted breeding for chickpea improvement. The present chapter discusses the recent advances in the application and impact of the genomic tools in chickpea improvement.

\subsection{Marker-Assisted Selection for Chickpea Improvement}

In marker-assisted selection (MAS), the genotypes are selected based on the presence or absence of markers instead of the trait itself. The tight linkage between the markers and the major gene or QTL responsible for the trait is necessary for successful implementation of MAS in breeding programs. With the advances in new genomic tools and availability of a large amount of genomic resources, it is now possible to identify the strong associations between markers and traits.

Routine breeding programs involve the combining of two or more genes or QTLs controlling trait(s) of interest into a common genetic background. In this process, selection of plants having all favorable donor alleles based on phenotype for making backcrosses or generation advancement in each generation will be very difficult. In such circumstances, the application of MAS will be of a great help in the process of identifying plants carrying several targeted alleles whose effect on the phenotype is not recognizable. In chickpea, a large number of genomic resources were deployed for the identification of genes/QTLs controlling several qualitative and quantitative traits. Some of them are early-flowering-time genes (Gaur et al. 2016; Mallikarjuna et al. 2017), pod- and seed-related traits for enhancing heat tolerance (Pronob Paul, personal communication), vernalization response (Samineni et al. 2016), root-related traits for enhancing drought tolerance (Chandra et al. 2004; Varshney et al. 2014a), ascochyta blight resistance (Aryamanesh et al. 2010; Cho et al. 2004; Varshney et al. 2014b), fusarium wilt resistance (Sharma et al. 2004; Sharma et al. 2005; Tekeoglu et al. 2000), botrytis gray mold resistance (Anuradha et al. 2011), seed yield traits under salinity (Pushpavalli et al. 2015) and normal growing conditions (Gowda et al. 2011), 
double podding (Rajesh et al. 2002; Cho et al. 2002; Ali et al. 2010), flower color, and several other traits. Among these traits, practical application of QTLs identified for improving drought tolerance, fusarium wilt, and ascochyta blight diseases has been successfully demonstrated using marker-assisted backcrossing (MABC).

\section{Improvement of Drought Tolerance}

In case of drought tolerance, multi-disciplinary activities were converged to improve the response of chickpea to drought stress conditions. The architecture and function of the root system are expected to directly relate to the transpiration efficiency (TE) which in turn is responsible for water balance in the plant during moisture stress conditions. The results indicated that increasing drought tolerance via deep roots along with higher TE was the key trait most likely to give higher grain yield under drought stress conditions (Soltani et al. 2000). Even though roots play a vital role in the extraction of water from the soil layers, very less information about the extent of variation and genetic behavior of these traits was revealed. The reason is obvious that phenotyping of these traits is highly labor-intensive and high influence of growing conditions on the results recorded.

Efforts from physiologists led to the identification of large variation for various root-related traits in the germplasm (Kashiwagi et al. 2005) and RILs (Serraj et al. 2004) that help reduce the negative effects of drought. In this direction, the root length density (RLD) in relatively shallow soil layers and the maximum root depth (RDp) were found to positively influence the seed yield under terminal drought environments (Gaur et al. 2008). One RIL population from Annigeri x ICC 4958 cross was developed and phenotyped for root traits (Serraj et al. 2004). Further, based on the results from screening of chickpea germplasm, two intraspecific mapping populations, namely ICC $4958 \times$ ICC 1882 and ICC $283 \times$ ICC 8261, were developed at ICRISAT (Gaur et al. 2008). These populations were evaluated at multi-locations over multi-seasons in India and genotyped with SSR markers. Results showed that a genomic region referred as "QTL-hotspot" showing $58.20 \%$ phenotypic variation for 12 drought tolerance-related traits including root traits was identified on CaLG04 (Varshney et al. 2014a). The "QTL-hotspot," validated in both RIL populations, increased the confidence of chickpea breeders to introgress this genomic region into popular chickpea cultivars for enhancing drought tolerance.

MABC aims to transfer one or more genes/QTLs of interest from one genetic background into popular or elite cultivar to improve the targeted trait. In this direction, chickpea varieties, JG 11, ICCV 10, and KAK 2 from India and Chefe from Ethiopia, were selected to introgress this genomic region from ICC 4958 genotype using MABC scheme. After making three backcrosses and selfing for 4 generations, more than $20 \mathrm{BC}_{3} \mathrm{~F}_{4}$ introgression lines were developed in each background of JG 11 and ICCV 10. A number of plants selected in each generation for making crosses and the markers used in the foreground and background selection for improving JG 11 were reported in Varshney et al. (2014a). These lines were evaluated at multi-locations for two years during 2011-2014 in India. Several lines giving at least $10 \%$ higher seed yield than recurrent parents (JG 11 and ICCV 10) were identified under both rainfed and irrigated conditions. Location-specific genotypes identified and very few genotypes found common in the top yielding lines due to high influence of environment. Interestingly, there was no relationship between yield under rainfed and irrigated conditions. Further, the seed size of most of the lines was increased which is similar to donor parent (ICC 4958). It indicates that the QTL-hotspot region was also influencing/close to genes controlling seed size in ICC 4958.

\section{Heat Stress Tolerance}

Increase in temperatures due to global warming reduces accumulation of assimilates, enhances 
leaf senescence, disturbs fertilization activities, and thus drastically reduces seed yield of crops, especially in combination with drought stress. As a result, plants show shortened life cycles, less time for photosynthesis (Reynolds et al. 2010), a shorter reproductive phase, and lower yield potential (Ainsworth and Ort 2010).

Being adapted to cool-season environments, cultivation of chickpea under increased day and night temperatures is a big challenge ahead. Recent screening efforts identified several heat-tolerant genotypes in chickpea (Wang et al. 2006; Krishnamurthy et al. 2011; Upadhyaya et al. 2011; Devasirvatham et al. 2012; Gaur et al. 2015). The ability of heat tolerance varies with cultivars and could involve changes in both morphological and physiological traits (Karim et al. 2000; Kumar et al. 2012), and therefore, heat-tolerant genotypes could be of great promise toward achieving stable yields under increasing temperatures. In this direction, a recent study was conducted to identify genomic regions related to heat tolerance in $\mathrm{F}_{8-9}$ recombinant inbred line (RIL) population of the cross ICC 4567 (heat sensitive) $\times$ ICC 15614 (heat tolerant). Phenotypic evaluation was done under field conditions with no stress and heat stress treatments. Genotyping-by-sequencing (GBS) approach based on 271 single nucleotide polymorphisms (SNPs) covering the whole genome of chickpea was used for genotyping. The QTL analysis revealed two consistent genomic regions harboring eight QTLs on CaLG05 and CaLG06. Four major QTLs for number of filled pods, number of seeds, grain yield, and \% pod setting, located in the CaLG05 genomic region, were found to have cumulative phenotypic variation of above 50\%. Moreover, QTL $\times$ environment interaction effects were non-significant except for harvest index and biomass (Pronob Paul, personal communication). Validation of these QTLs in other populations is in progress, and once these are validated, MAS can be effectively implemented in regular breeding programs for enhancing heat tolerance.

\section{Enhancement of Genetic Diversity Through MAGIC (Multi-parent Advanced Generation Intercrossing) Lines}

The existence of genetic diversity in the breeding populations is crucial to develop new varieties with resistance to various biotic and abiotic stresses. Using different hybridization techniques, plant breeders create variability for various traits of economic importance, which will expose the rare or important alleles in homozygous condition. In this direction, MAGIC lines were developed in chickpea using eight diverse genotypes selected from South Asia and sub-Saharan Africa. In this development scheme, more number of recombinations and greater genetic diversity in MAGIC lines greatly help in detection of QTLs with high precision. Further, these lines can be used directly in breeding programs for the development of cultivars suitable to diverse agro-ecologies in Asia and sub-Saharan Africa. The incorporation of multiple parents ensures the population segregates for multiple QTLs for multiple traits. Further, MAGIC lines can act as a base for gene discovery, characterization, and deployment of genes for understanding complex traits (Glaszman et al. 2010). The power of such populations has been demonstrated in maize to understand the genetic architecture of several traits (Buckler et al. 2009; Poland et al. 2011).

The parents (ICC 4958, ICCV 10, JAKI 9218, JG 11, JG 130, JG 16, ICCV 97105, and ICCV 00108) of the MAGIC lines from Ethiopia, Kenya, and India were crossed in direct fashion excluding reciprocals. Twenty-eight two-way, 14 four-way, and 7 eight-way crosses were made to develop a MAGIC population. Over $1200 \mathrm{~F}_{2}$ plants from 7 eight-way crosses were advanced to $\mathrm{F}_{8}$ using single seed descent (SSD) method and seed was harvested from $1136 \mathrm{~F}_{7: 8}$ progenies. These progenies were evaluated for two years (2013 and 2014) under field conditions with rainfed and irrigated treatments. Large 
variability in phenology (days to flowering: 34$69 \mathrm{~d}$ ) and yield-related traits (seed yield: 170$4554 \mathrm{~kg} / \mathrm{ha}$ ); 100 seed weight: 10-45 g) was observed under two treatments (Gaur et al. unpublished data). Several promising lines with significantly higher seed yield than the best parents were also identified. On the other hand, eight parents used in the development of MAGIC lines were genotyped using 70 SSR and 747 SNP markers. In addition, the parental lines were resequenced (with 5.79-16.08X coverage) and variable number of SNPs and indels were identified among the parental lines by aligning to $\mathrm{CDC}$ Frontier reference genome. The $\mathrm{F}_{8}$ progenies were also genotyped for identification of diverse MAGIC lines based on haplotype distribution. MAGIC lines will be a valuable source for establishing marker-trait association using genome-wide association study (GWAS) for several complex traits in chickpea.

\section{Marker-Assisted Recurrent Selection (MARS) for Yield Enhancement}

Many complex traits are controlled by several minor QTLs. Gene pyramiding becomes very difficult as the number of QTLs increases, and in such cases, MABC has limited application. The more effective strategy would be to deploy MARS to increase the frequency of favorable alleles in the populations. This molecular breeding scheme differs from traditional QTL or MAS studies in that the new mapping study is conducted on each breeding population. This technology was developed first by major commercial maize breeding programs, and it has shown promising in increasing the rate of genetic gain. To evaluate the application of MARS scheme in self-pollinated crops such as chickpea, experiments were conducted with the support from Generation Challenge Program (GCP) during 2010-2014 at ICRISAT, Patancheru, India. Choice of populations was driven by yield performance of genotypes. Two crosses JG $11 \times$ ICCV 04112 and JG $130 \times$ ICCV 05107 were made to combine the favorable alleles of yield QTLs from the respective parents with an assumption that each population had a different set of QTLs involved. $188 \mathrm{~F}_{3}$ plants each in two crosses were genotyped using SSR markers. Further, $\mathrm{F}_{3}$-derived $\mathrm{F}_{5}$ progenies were evaluated at multi-locations. QTL analysis of phenotyping and genotyping data resulted in identification of few major and several minor QTLs contributing to yield, and yield contributing traits (RK Varshney, personal communication). Based on the QTL(s) information for seed yield, harvest index, biomass, and seed size in different $\mathrm{F}_{5}$ progenies, 4 lines were selected in JG $11 \times$ ICCV 04112 and 3 lines in JG $130 \times$ ICCV 05107 having different combinations of favorable alleles for recombination cycle. Multiple cycles of MARS increased the frequency of favorable marker alleles associated with agronomic traits. The selected lines were subjected to 1st and 2nd recombination cycles. $F_{1}$ plants (27 and 5) having all favorable alleles of QTLs from both parents for seed yield and other yield-related traits were identified in JG $11 \times$ ICCV 04112 and JG $130 \times \mathrm{ICCV}$ 05107, respectively. Finally, $\mathrm{F}_{1}$ plants with all favorable alleles in homozygous condition were grown. Each selected $F_{1}$ plant was advanced to $F_{4}$ generation separately for field evaluation. On the other hand, for comparing the advantage of MARS over the traditional method of recurrent selection, top 8 high-yielding $\mathrm{F}_{5}$ progenies were also selected and intercrossing is being completed in each cross. Practical utility of this scheme in regular breeding programs will depend on the genetic gain achieved in terms of selection efficiency, selection accuracy, marker-trait associations, and distribution of favorable alleles between the selected parents used for crossing. Further, marker technology helps in the identification of individual plants having all favorable alleles among large populations when the number of loci of interest is higher, and in identifying whether the genotype combining favorable alleles is present in the population (Ishii and Yonezawa 2007). The utility of MARS decreases as the information of the number of small-effect QTLs associated with the trait decreases (Charcosset and Moreau 2004; Bernardo and Charcosset 2006). However, Bernardo and Charcosset (2006) reported that the higher genetic gain was feasible through MARS compared to MABC. 


\section{Application of MARS in chickpea}

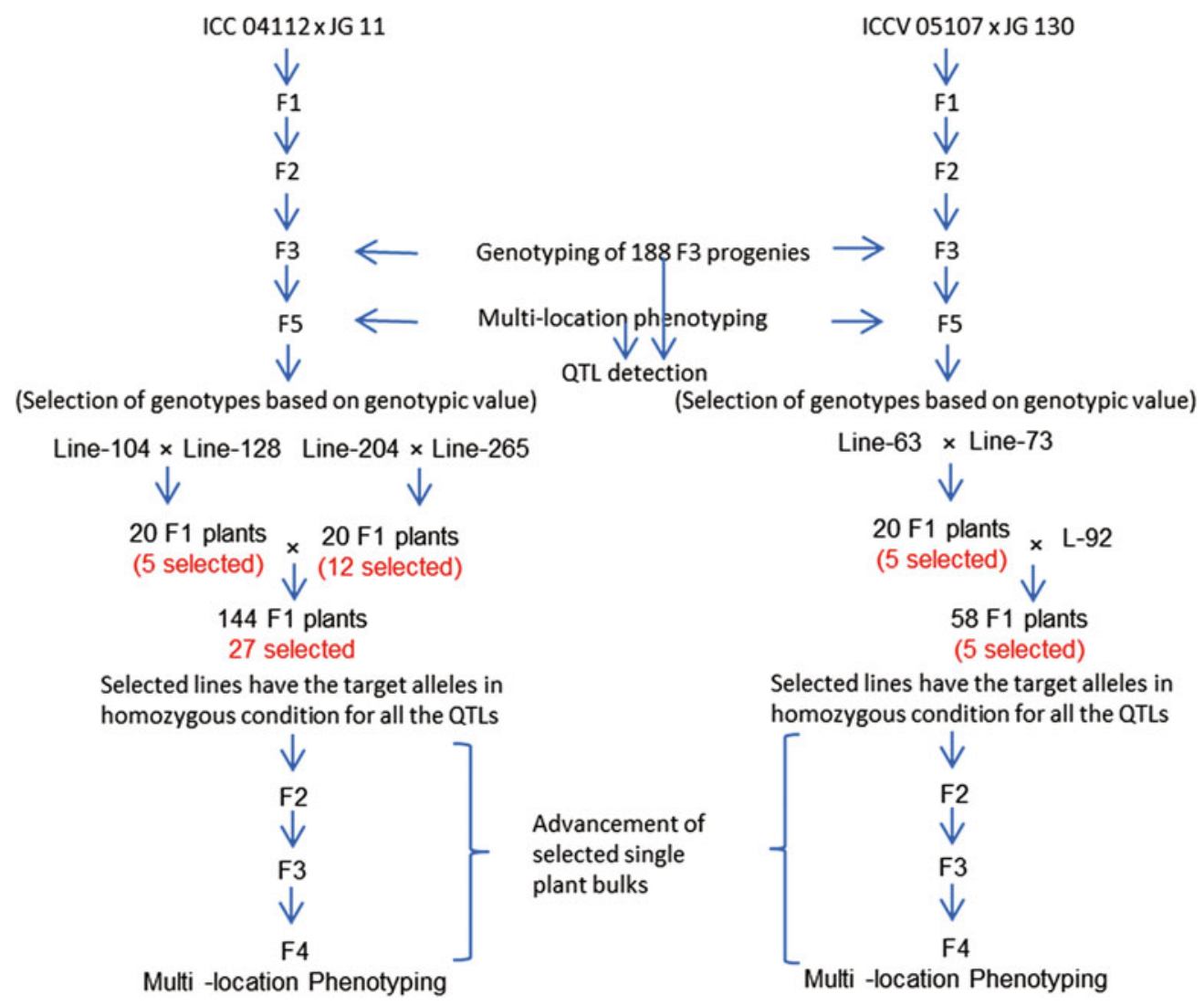

\section{Introgression of Fusarium Wilt and Ascochyta Blight Resistance into Elite Cultivar}

In chickpea, genes from different sources which confer resistance against fusarium wilt and ascochyta blight (Ascochyta rabiei) diseases have been successfully transferred and genotypes were developed with resistance to fusarium wilt and ascochyta blight diseases. Wilt is the most commonly occurring disease in warm and dry regions. Several stable sources of resistance were identified (Haware and Nene 1982; Nene et al. 1989; Pande et al. 2006) and successfully integrated into the backgrounds of high-yielding lines in the regular breeding programs for enhancing the wilt resistance. Further, the available field and laboratory screening technologies are cost-effective, yet reliable. However, availability of molecular markers associated with wilt resistance genes could accelerate the selection of resistant genotypes. Using the marker-assisted selection, markers tightly linked to wilt resistance genes can be used to screen a large number of genotypes for the presence of these genes. For example, SSR marker "TA59" has been used to tag genes for wilt resistance in the NIL development (Castro et al. 2010). Several studies suggest the existence of a genomic region harboring several resistance genes in linkage group 2 (LG2), including a cluster of six fusarium wilt resistance genes: foc- 0 , foc- 1 , foc -2 , foc -3 , foc- 4 , and foc-5 (Tekeoglu et al. 2000; Winter et al. 2000; Cobos et al. 2005; Milla'n et al. 2006; Sharma and Muehlbauer 2007; Halila et al. 2009). Identifying reliable race-specific 
diagnostic markers will further enhance the application of molecular markers in regular breeding programs. These markers help in the identification of sources of resistance to different races simultaneously, which has been a difficult task under field screening.

Ascochyta blight $(\mathrm{AB})$ is a major disease of chickpea, especially in areas where cool, and humid weather persists during the crop season. Several sources of resistance to $\mathrm{AB}$ were identified (Reddy and Singh 1984; Singh and Kapoor 1985; Singh and Reddy 1990). Breeding efforts at ICRISAT led to the development of varieties with moderate to good level of resistance to $A B$ were released in the names of "Myles" and "Howzat" in USA and Australia, respectively. Genetic studies reported that $\mathrm{AB}$ resistance of chickpea is oligogenic in nature. Studies on RILs suggest that several genomic regions (QTLs) were involved in controlling resistance to $A B$ dispersed on different linkage groups (LG2, LG3, LG4, LG6, and LG8) in the genome. LG4 has been reported by several researchers to contain QTLs for AB resistance (Santra et al. 2000; Tekeoglu et al. 2002; Cho et al. 2004; Stephens et al. 2014), while other reports highlight LG2 (Udupa and Baum 2003; Cho et al. 2004), LG3 (Flandez-Galvez et al. 2003b; Anbessa et al. 2009; Kanouni et al. 2009), and LG8 (Lichtenzveig et al. 2006). Markers closely linked to major QTLs have been reported. Two QTLs for pathotype II located on LG4, one is linked to markers CaETR or GAA47 and the other is linked to TA72/ScY17 (Udupa and Baum 2003; Cho et al. 2004). Furthermore, loci TS12b and STMS28 on LG1 and TS45 and TA3b on LG2 were found significantly associated with the disease reaction under controlled environments (Flandez et al. 2003a and b). Similarly, a codominant marker (CaETR) located in the QTLAR1 region of LG4 was also reported (Madrid et al. 2013). However, these markers linked to different AB QTLs need to be validated in diverse populations for their utility in regular breeding programs.
In this direction, an attempt was made to introgress the QTLs controlling FW and AB into a cultivar, C 214 (Varshney et al. 2014). In the foreground selection, six SSR markers (TR19, TA194, TAA60, GA16, TA110, and TS82) linked to foc-1 for FW, and eight markers (TA194, TR58, TS82, GA16, SCY17, TA130, TA2, and GAA47) linked to ABQTL-I and ABQTL-II for AB were used in MABC scheme. After three backcrosses, FW-resistant lines with more than $90 \%$ recovery and AB-resistant lines with more than $80 \%$ recovery of recurrent parent genome were selected. These lines need to be evaluated under field conditions for disease response and agronomic performance in multi-location trials for possible application of these markers.

\subsection{Conclusion}

New genomic advances, many of which are already being developed, will make it easier for breeders to obtain new cultivars with improved characteristics, either by facilitating selection or by improving the variation available by using precision breeding approaches. In particular, the present and new genomics tools add great value in the process of genetic dissection and breeding of complex traits. So far, the genomic tools played a key role in QTL identification, and their use in chickpea breeding programs is limited to improving drought tolerance. Identification of reliable diagnostic markers for several other important traits should be given more emphasis for rapid spreading of this technology in NARS breeding programs.

\section{References}

Ainsworth EA, Ort DR (2010) How do we improve crop production in a warming world? Plant Physiol 154:526-530

Ali H, Shah TM, Iqbal N, Atta BM, Haq MA (2010) Mutagenic induction of double-podding trait in 
different genotypes of chickpea and their characterization by STMS marker. Plant Breed 129:116-119

Anbessa Y, Taran B, Warkentin TD, Tullu A, Vandenberg A (2009) Genetic analyses and conservation of QTL for Ascochyta blight resistance in chickpea (Cicer arietinum L.). Theor Appl Genet 4:757-765

Anuradha Ch, Gaur PM, Pande S, Gali KK, Ganesh M, Kumar J, Varshney RK (2011) Mapping QTL for resistance to botrytis grey mould in chickpea. Euphytica 182:1-9

Aryamanesh N, Nelson MN, Yan G, Clarke HJ, Siddique KHM (2010) Mapping a major gene for growth habit and QTLs for ascochyta blight resistance and flowering time in a population between chickpea and Cicer reticulatum. Euphytica 173:307-319

Bernardo R, Charcosset A (2006) Usefulness of gene information in marker-assisted recurrent selection: a simulation appraisal. Crop Sci 46:614-621

Buckler ES, Holland JB, Bradbury PJ, Acharya CB, Brown PJ, Browne C, Ersoz E, Flint-Garcia S, Garcia A, Glaubitz JC, Goodman MM, Harjes C, Guill K, Kroon DE, Larsson S, Lepak NK, Li H, Mitchell SE, Pressoir G, Peiffer JA, Rosas MO, Rocheford TR, Romay MC, Romero S, Salvo S, Villeda HS, da Silva HS, Sun Q, Tian F, Upadyayula N, Ware D, Yates H, Yu J, Zhang Z, Kresovich S, McMullen MD (2009) The genetic architecture of maize flowering time. Science 325:714-718. http://science.sciencemag.org/content/ 325/5941/714

Castro P, Pisto'n F, Madrid E, Milla`n T, Gil J, Rubio J (2010) Development of chickpea near-isogenic lines for Fusarium wilt. Theor Appl Genet 121:1519-1526

Chandra S, Buhariwalla HK, Kashiwagi J, Harikrishna S, Sridevi KR, Krishnamurthy L, Serraj R, Crouch JH, (2004) Identifying QTL-linked markers in marker-deficient crops. In: Fisher T. (ed) Proceedings of the 4th International Crop Science Congress. Brisbane, Australia, 26 September-1 October 2004. The Regional Institute Ltd., Gosford, New South Wales, Australia

Charcosset A, Moreau L (2004) Use of molecular markers for the development of new cultivars and the evaluation of genetic diversity. Euphytica 137:81-94

Cho S, Chen W, Muehlbauer FJ (2004) Pathotype-specific genetic factors in chickpea (Cicer arietinum L.) for quantitative resistance to ascochyta blight. Theor Appl Genet 109:733-739

Cho S, Kumar J, Shultz JL, Anupama K, Tefera F, Muehlbauer FJ (2002) Mapping genes for double podding and other morphological traits in chickpea. Euphytica 128:285-292

Cobos MJ, Ferna`ndez MJ, Rubio J, Kharrat M, Moreno MT, Gil J, Milla`n T (2005) A linkage map of chickpea (Cicer arietinum L.) based on populations from Kabuli 9 Desi crosses: location of genes for resistance to Fusarium wilt race 0. Theor Appl Genet 110:1347-1353

Devasirvatham V, Gaur PM, Mallikarjuna N, Raju TN, Trethowan RM, Tan DKY (2012) Effect of high temperature on the reproductive development of chickpea genotypes under controlled environments. Funct Plant Biol 39:1009-1018

FAOSTAT (2016) http://faostat3.fao.org/download/Q/ QC/E. Accessed 11 Sept 2016

Flandez-Galvez H, Ades R, Ford R, Pang E, Taylor P (2003a) QTL analysis for ascochyta blight resistance in an intraspecific population of chickpea (Cicer arietinum L.). Theor Appl Genet 107:1257-1265

Flandez-Galvez H, Ford R, Pang ECK, Taylor PWJ (2003b) An intraspecific linkage map of the chickpea (Cicer arietinum L.) genome based on sequence-tagged microsatellite site and resistance gene analog markers. Theor Appl Genet 106:1447-1456

Gaur PM, Krishnamurthy L, Kashiwagi J (2008) Improving drought-avoidance root traits in chickpea (Cicer arietinum L.) - current status of research at ICRISAT. Plant Prod Sci 11:3-11

Gaur PM, Samineni S, Krishnamurthy L, Kumar S, Ghanem ME, Beebe S, Rao I, Chaturvedi SK, Basu PS, Nayyar H, Jayalakshmi V, Babbar A, Varshney RK (2015) High temperature tolerance in grain legumes. Legume Perspect 7:23-24

Gaur PM, Samineni S, Tripathi S, Varshney RK, Gowda CLL (2016) Allelic relationships of flowering time genes in chickpea. Euphytica 203:295-308

Glaszmann JC, Kilian G, Upadhyaya HD, Varshney RK (2010) Accessing genetic diversity for crop improvement. Curr Opin Plant Biol 13:167-173

Gowda SJM, Radhika P, Mhase LB, Jamadagni BM, Gupta VS, Kadoo NY (2011) Mapping of QTLs governing agronomic and yield traits in chickpea. J Appl Genet 52:9-21

Halila I, Cobos MJ, Rubio J, Millán T, Kharrat M, Marrakchi M, Gil J (2009) Tagging and mapping a second resistance gene for Fusarium wilt race 0 in chickpea. Eur J Plant Pathol 124:87-92

Haware MP, Nene YL (1982) Races of Fusarium oxysporum f. sp. ciceris. Plant Dis 66:809-810

Ishii T, Yonezawa K (2007) Optimization of the marker-based procedures for pyramiding genes from multiple donor lines: II. Strategies for selecting the objective homozygous plant. Crop Sci 47:1878-1886

Kanouni H, Taleei A, Peyghambari SA, Okhovat SM, Baum M, Abang M (2009) QTL analysis for ascochyta blight resistance in chickpea (Cicer arietinum L.) using microsatellite markers. J Agric Res 25:109-127

Karim MA, Fracheboud Y, Stamp P (2000) Effect of high temperature on seedling growth and photosynthesis of tropical maize genotypes. J Agron Crop Sci 184:217223

Kashiwagi J, Krishnamurthy L, Upadhyaya HD, Krishna H, Chandra S, Vadez V, Serraj R (2005) Genetic variability of drought-avoidance root traits in the mini-core germplasm collection of chickpea (Cicer arietinum L.). Euphytica 146:213-222

Krishnamurthy L, Gaur PM, Basu PS, Chaturvedi SK, Tripathi S, Vadez V, Rathore A, Varshney RK, Gowda CLL (2011) Large genetic variation for heat 
tolerance in the reference collection of chickpea (Cicer arietinum L.) germplasm. Plant Genet Resour 9:59-69

Kumar S, Kaushal N, Nayyar H, Gaur PM (2012) Abscisic acid induces heat tolerance in chickpea (Cicer arietinum L.) seedlings by facilitated accumulation of osmo protectants. Acta Physiol Plant 34:1651

Lichtenzveig J, Bonfil DJ, Zhang HB, Shtienberg D, Abbo S (2006) Mapping quantitative trait loci in chickpea associated with time to flowering and resistance to Didymella rabiei the causal agent of Ascochyta blight. Theor Appl Genet 113:1357-1369

Madrid E, Chen W, Rajesh PN, Castro P, Millan T, Gil J (2013) Allele-specific amplification for the detection of Ascochyta blight resistance in chickpea. Euphytica 189:183-190

Mallikarjuna BP, Samineni S, Thudi M, Sajja SB, Khan AW, Patil A, Viswanatha KP, Varshney RK, Gaur PM (2017) Molecular mapping of flowering time major genes and QTLs in Chickpea (Cicer arietinum L.). Front Plan Sci 8

Millán T, Clarke HJ, Siddique KHM, Buhariwalla HK, Gaur PM, Kumar J, Gill J, Kahl G, Winter P (2006) Chickpea molecular breeding: new tools and concepts. Euphytica 147:81-103

Morgante M, Salamini F (2003) From plant genomics to breeding practice. Curr Opin Biotechnol 14:214-219

Nene YL, Haware MP, Reddy NMV, Philps JP, Castro EL, Kotasthane SR, Gupta O, Singh G, Shukia P, Sah RP (1989) Identification of broad based and stable resistance to wilt and root-rots in chickpea. Ind Phytopathol 42:499-505

Pande S, Kishore GK, Upadhyaya HD, Rao JN (2006) Identification of sources of multiple disease resistance in mini-core collection of chickpea. Plant Dis 90:1214-1218

Poland JA, Bradbury PJ, Buckler ES, Nelson RJ (2011) Genome-wide nested association mapping of quantitative resistance to northern leaf blight in maize. Proc Natl Acad Sci USA 108:6893-6898

Pushpavalli R, Krishnamurthy L, Thudi M, Gaur PM, Rao MV, Siddique KHM, Colmer TD, Turner NC, Varshney RK, Vadez V (2015) Two key genomic regions harbour QTLs for salinity tolerance in ICCV $2 \times$ JG 11 derived chickpea (Cicer arietinum L.) recombinant inbred lines. BMC Plant Biol 15:124

Rajesh P, Tullu A, Gil J, Gupta V, Ranjekar P, Muehlbauer F (2002) Identification of an STMS marker for the double-podding gene in chickpea. Theor Appl Genet 105:604-607

Reddy MV, Singh KB (1984) Evaluation of a world collectionof chickpea germplasm accessions for resistance to ascochytablight. Plant Dis 68:900-901

Reynolds MP, Hays D, Chapman S (2010) Breeding for adaptation to heat and drought stress. In: Change Climate, Production Crop (eds) MP Reynolds. CABI, Oxfordshire, pp 71-91

Samineni S, Kamatam S, Thudi S, Varshney RK, Gaur PM (2016) Vernalization response in chickpea is controlled by a major QTL. Euphytica 207:453-461
Santra DK, Tekeoglu M, Ratnaparkhe M, Kaiser WJ, Muehlbauer FJ (2000) Identification and mapping of QTLs conferring resistance to Ascochyta blight in chickpea. Crop Sci 40:1606-1612

Serraj R, Krishnamurthy L, Kashiwagi J, Kumar J, Chandra S, Crouch JH (2004) Variation in root traits of chickpea (Cicer arietinum L.) grown under terminal drought. Field Crops Res 88:115-127

Sharma KD, Chen W, Muehlbauer FJ (2005) Genetics of chickpea resistance to five races of usarium wilt and a concise set of race differentials for Fusarium oxysporum f. sp. ciceris. Plant Dis 89:385-390

Sharma KD, Muehlbauer FJ (2007) Fusarium wilt of chickpea: physiological specialization, genetics of resistance and resistance gene tagging. Euphytica 157:1-14

Sharma KD, Winter P, Kahl G, Muehlbauer FJ (2004) Molecular mapping of Fusarium oxysporum $\mathrm{f}$. sp. ciceris race 3 resistance gene in chickpea. Theor Appl Genet 108:1243-1248

Singh G, Kapoor S (1985) Screening for combined resistance to botrytis gray mold and Ascochyta blight of chickpea. Int Chickpea Newsl 12:21-22

Singh KB, Reddy MV (1990) Patterns of resistance and susceptibility to races of A. rabiei among germplasm accessions and breeding lines of chickpea. Plant Dis 74:127-129

Soltani A, Khooie FR, Ghassemi-Golezani K, Moghaddam M (2000) Thresholds for chickpea leaf expansion and transpiration response to soil water deficit. Field Crops Res 68:205-210

Stephens A, Lombardi M, Cogan NOI, Forster JW, Hobson K, Materne M, Kaur S (2014) Genetic marker discovery, interspecific linkage map construction and quantitative trait locus analysis of ascochyta blight resistance in chickpea (Cicer arietinum L.). Mol Breeding 33:297-313

Tekeoglu M, Rajesh PN, Muehlbauer FJ (2002) Integration of sequence tagged microsatellite sites to the chickpea genetic map. Theor Appl Genet 105:847854

Tekeoglu M, Tullu A, Kaiser WJ, Muehlbauer FJ (2000) Inheritance and linkage of two genes that confer resistance to Fusarium wilt in chickpea. Crop Sci 40:1247-1251

Thudi M, Khan AW, Vinay Kumar, Gaur PM, Katta K, Garg V, Roorkiwal M, Samineni S, Varshney RK (2016) Whole genome re-sequencing reveals genome-wide variations among parental lines of 16 mapping populations in chickpea (Cicer arietinum L.). BMC Plant Biol 16:10

Udupa SM, Baum M (2003) Genetic dissection of patho type specific resistance to Ascochyta blight disease in chickpea (Cicer arietinum L.) using microsatellite markers. Theor Appl Genet 106:1196-1202

Upadhyaya HD, Dronavalli N, Gowda CLL, Singh S (2011) Identification and evaluation of chickpea germplasm for tolerance to heat stress. Crop Sci 51:2079-2094 
Varshney RK, Glaszmann J-C, Leung H, Ribaut JM (2010) More genomic resources for less-studied crops. Trends Biotechnol 28:452-460

Varshney RK, Thudi M, Nayak SN, Gaur PM, Kashiwagi J, Krishnamurthy L, Jaganathan D, Koppolu J, Bohra A, Tripathi S, Rathore A, Jukanti AK, Jayalakshmi V, Vemula A, Singh SJ, Yasin M, Sheshshayee MS, Viswanatha KP (2014a) Genetic dissection of drought tolerance in chickpea (Cicer arietinum L.). Theor Appl Genet 127:445-462

Varshney RK, Mohan SM, Gaur PM, Chamarthi SK, Singh VK, Samineni S, Swapna N, Sharma M, Singh S, Kaur L, Pande S (2014b) Marker-assisted backcrossing to introgress resistance to Fusarium wilt (FW) race 1 and Ascochyta blight (AB) in C 214, an elite cultivar of chickpea. Plant Genome 7:1

Varshney RK, Song C, Saxena RK, Azam S, Yu S, Sharpe A, Cannon S, Baek J, Rosen BD, Tar'an B, Millan T, Zhang X, Ramsay LD, Iwata A, Wang Y, Nelson W, Farmer AD, Gaur PM, Soderlund C, Penmetsa RV, Xu C, Bharti AK, He W, Winter P, Zhao S, Hane JK, Garcia NC, Condie JA, Upad- hyaya HD, Luo MC, Thudi M, Gowda CLL, Singh NP, Lichtenzveig J, Gali KK, Rubio J, Nadarajan N, Dolezel1 J, Bansal KC, Xu X, Edwards D, Zhang G, Kahl G, Gil J, Singh KB, Datta SK, Jackson SA, Wang J, Cook DR (2013). Draft genome sequence of chickpea (Cicer arietinum) provides a resource for trait improvement. Nat Biotechnol 31:240-246

Vaughan DA, Balász E, Heslop-Harrison JS (2007) From crop domestication to super-domestication. Ann Bot 100:893-901

Wang J, Gan YT, Clarke F, McDonald CL (2006) Response of chickpea yield to high temperature stress during reproductive development. Crop Sci 46:21712178

Winter P, Benko-Iseppon AM, Hu“ttel B, Ratnaparkhe M, Tullu A, Sonnante G, Pfaff T, Tekeoglu M, Santra D, Sant VJ, Rajesh PN, Kahl G, Muehlbauer FJ (2000) A linkage map of the chickpea (Cicer arietinum L.) genome based on recombinant inbred lines from a C. arietinum 9 C. reticulatum cross: localization of resistance genes for Fusarium wilt races 4 and 5 . Theor Appl Genet 101:1155-1163 